\title{
Sự truyền dẫn giá bán của tôm sú trong thị trường
}

\section{Price transmission in black tiger shrimp market}

\author{
Lê Nhị Bảo Ngọc ${ }^{1 *}$, Lê Quang Thông² , Thái Anh Hòa ${ }^{3}$ \\ ${ }^{1}$ Trường Cao đẳng Cộng đồng Cà Mau, Việt Nam \\ ${ }^{2}$ Trường Đại học Nông Lâm Thành phố Hồ Chí Minh, Việt Nam \\ ${ }^{3}$ Trường Đại học Trà Vinh, Việt Nam \\ *Tác giả liên hệ, Email: baongoccamau80@gmail.com
}

\section{THÔNG TIN}

DOI: 10.46223/HCMCOUJS.

econ.vi.13.1.1615.2018

Ngày nhận: 21/11/2017

Ngày nhận lại: 01/03/2018

Duyệt đăng: 14/03/2018

Tù khóa:

hội nhập thị trường, điều chỉnh giá, mô hình hiệu chỉnh sai số (ECM), sự truyền dẫn giá, thị trường tôm sú

\section{Keywords:}

black tiger shrimp markets, Error Correction Model (ECM), market integration, price adjustment, price transmission

\section{TÓM TÁT}

Nghiên cứu này nhằm mục tiêu xem xét mối quan hệ giữa giá bán tôm sú tại cổng trại với giá bán lẻ nội địa và giá xuất khẩu trong ngắn hạn và dài hạn ở tỉnh Cà Mau. Số liệu chuỗi thời gian từ tháng 9/2011 đến tháng 4/2017 được sử dụng cho phân tích. Mối quan hệ giữa các mức giá được phân tích dựa vào việc kiểm định nghiệm đơn vị (ADF), ước lượng mô hình hiệu chỉnh sai số $\mathrm{ECM}$ và ước lượng mô hình bình phương nhỏ nhất (OLS). Kết quả nghiên cứu đã chỉ ra trong dài hạn giá bán tôm sú tại cổng trại có mối quan hệ đồng liên kết và tác động cùng chiều với giá bán lẻ nội địa và giá xuất khẩu. Trong khi đó, mối quan hệ giữa giá xuất khẩu và giá tôm sú bán tại cổng trại không có ý nghĩa thống kê. Ngoài ra, kết quả nghiên cứu cũng cho thấy sự mất cân bằng của giá cổng trại trên thị trường trong tháng trước sẽ được điều chỉnh theo chiều ngược lại trong tháng sau.

ABSTRACT
This study aims to identify the transmission from domestic
and export prices to farm-gate prices of tiger shrimp in Ca Mau
province. Monthly series data for the analysis were collected
from September 2011 to April 2017. An error correction
mechanism (ECM) and linear regression model of farm- gate
prices were used to explore the price transmission from domestic
and export prices to farm gate prices. Research results show that
in the long run, the prices of black tiger shrimp at farm gate
integrate with the domestic and export prices and they positively
correlate. In the short run, domestic prices are likely to have a
significant effect on farm-gate prices. In fact, the relationship
between export prices and farm gate prices is not statistically
significant. It is also found that the dis-equilibrium of the farm


gate prices on the market was adjusted for the subsequent month through the error-correction mechanism.

\section{1. Đặt vấn đề}

Đối với bất kỳ một loại hàng hóa nào, giá luôn là một trong những yếu tố quyết định đến sự tồn tại của hàng hóa đó trên thị trường và luôn là mối quan tâm hàng đầu của người sản xuất lẫn người tiêu dùng. Giá hàng hóa là căn cứ và là tín hiệu quan trọng để giúp cho doanh nghiệp xây dựng các phương án kinh doanh và kế hoạch sản xuất phù hợp. Giá hàng hóa được hình thành trên thị trường không chỉ căn cứ vào chi phí của một đơn vị sản phẩm mà còn phải dựa vào quan hệ giữa cung và cầu đối với sản phẩm trên thị trường. Giá cũng là kết quả của sự tương tác của nhiều mối quan hệ trong nền kinh tế, trong đó có mối quan hệ về giá giữa các tác nhân trong chuỗi giá trị của sản phẩm (Norwood \& Lusk, 2008).

Giá tôm sú trên thị trường, đặc biệt giá cổng trại bị chi phối nhiều bởi những tác nhân trong chuỗi giá trị. Kênh tiêu thụ chính của tôm nước lợ vùng Đồng bằng sông Cửu Long (ĐBSCL) có nhiều tác nhân trung gian ${ }^{1}$, bao gồm thu gom, thương lái, người bán lẻ, doanh nghiệp chế biến và các công ty chế biến xuất khẩu (N. V. G. Le, Le, \& Nguyen, 2012; S. X. Le, Do, Nguyen, \& Nguyen, 2011). Do vậy, giá cổng trại có thể được hình thành từ sự truyền dẫn giá từ thị trường bán lẻ và xuất khẩu qua các tác nhân trong chuỗi và đến nông trại. Hoạt động mua bán tôm do thương lái/đại lý (các trung gian) thường được diễn ra tại ao nuôi và giá tại cổng trại được xác định dựa trên thông tin về giá ở các thị trường đầu ra trong kênh. Có sự khác biệt giá tôm theo cỡ tôm. Tôm sau khi thu mua được phân loại cỡ tôm hoặc sơ chế và chuyển đến các nhà máy chế biến, doanh nghiệp chế biến thủy sản xuất khẩu (CBTSXK) có nhu cầu. Kênh tiêu thụ chính của tôm sú đi từ nông dân đến thị trường bán lẻ, và nhà máy chế biến xuất khẩu chủ yếu qua các trung gian theo hình thức mua xô (Bộ NN\&PTNT \& Viện Kinh tế và Quy hoạch thủy sản, 2015).

Giá xuất khẩu tăng là tín hiệu tốt cho các doanh nghiệp CBTSXK tăng sản lượng chế biến xuất khẩu, có nhiều doanh nghiệp tham gia ngành. Đồng thời, giá bán tại cổng trại tăng nông dân nuôi tôm có động cơ tăng sản lượng và mở rộng sản xuất. Nhưng khi giá xuất khẩu giảm khiến các doanh nghiệp xuất khẩu giảm mức độ sản xuất hoặc có thể đóng cửa nhà máy. Hệ quả là giá cổng trại giảm dẫn đến xu hướng nông dân giảm sản ượng hay chuyển sang đối tượng nuôi khác (Hiệp hội Chế biến và Xuất khẩu Thủy sản Việt Nam (VASEP), 2014, 2015). Do đó, việc nghiên cứu xác định tác động của giá xuất khẩu cũng như giá bán tại thị trường nội địa đối với giá bán tại cổng trại sẽ góp phần giúp người sản xuất tôm có thể dự báo được khuynh hướng thay đổi của giá tôm sú tại cổng trại dựa trên giá xuất khẩu hay giá tôm sú bán tại thị trường nội địa được công bố thường xuyên trên các bản tin thị trường, từ đó có những hoạch định sản xuất phù hợp.

Mặc dù, các nghiên cứu thực nghiệm nước ngoài đã xác định mối quan hệ trong ngắn hạn và dài hạn của giá ở thị trường bán sỉ và thị trường xuất khẩu đối với giá cổng trại tại các thị trường nông sản như Asche, Hartmann, Fofana, Jaffry, và Menezes (2002) đối với cá tuyết

\footnotetext{
${ }^{1}$ Thương lái (vựa) đi thu gom tôm nguyên liệu cho các nhà máy chế biến, có rất ít người nuôi tôm bán cho các doanh nghiệp chế biến thủy sản.
} 
tại Na-uy. Tuy nhiên, tại Việt Nam có rất ít nghiên cứu từ D. M. Nguyen (2012) đối với tôm sú tại ĐBSCL và $\mathrm{P}$. V. Nguyen và To (2014) đối với cà phê tại Việt Nam. Điển hình như nghiên cứu của D. M. Nguyen (2012) đã sử dụng lý thuyết về đồng liên kết (Cointegration theory) và mô hình ECM với chuỗi số liệu giá theo tháng từ tháng 1 năm 2007 đến tháng 12 năm 2010 được thu thập từ hai tỉnh thuộc ĐBSCL là Bến Tre và Sóc Trăng để kiểm định các tác động ngắn hạn và dài hạn về giá tôm sú ở các thị trường bán sỉ và thị trường xuất khẩu đối với giá bán tại cổng trại vùng ĐBSCL. Trong nghiên cứu này, tác giả sử dụng số liệu giá hàng tháng của tôm sú từ tháng 9 năm 2011 đến tháng 4 năm 2017 được thu thập từ Cục Thống kê và Sở Tài chính của tỉnh Cà Mau để ước lượng tác động của giá xuất khẩu và giá bán lẻ tại thị trường nội địa đến giá cổng trại của tôm sú trong ngắn hạn và dài hạn. Từ năm 2010 đến 2017, thị trường tôm trong và ngoài nước có sự biến động đáng kể do sự tác động của cuộc khủng hoảng tài chính và sự thay đổi khuynh hướng tiêu dùng trong nước và trên thế giới (VASEP, 2012, 2014, 2015) nên việc nghiên cứu với số liệu cập nhật sẽ cho thấy sự tiến triển của thị trường tôm sú trong giai đoạn có nhiều biến động (Bộ Công Thương, 2017; VASEP, 2017). Từ kết quả ượng mô hình tác động của giá xuất khẩu và giá bán lẻ tại thị trường nội địa đến giá cổng trại của tôm sú, tác giả đánh giá hiệu quả việc truyền dẫn giá bằng hệ số co giãn của giá xuất khẩu và giá bán lẻ đến giá cổng trại. Để đạt được các mục tiêu nghiên cứu đặt ra, tác giả sử dụng kiểm định nghiệm đơn vị với các chuỗi số liệu về giá và tiến hành ước ượng mô hình OLS và mô hình ECM. Đây là điểm khác biệt của nghiên cứu so với các nghiên cứu trước đây. Đồng thời, nghiên cứu sẽ giúp nông dân nuôi tôm có thêm thông tin về dự báo giá dựa trên sự biến động giá từ thị trường xuất khẩu và nội địa. Từ đó, người nuôi tôm có thể lập kế hoạch sản xuất kinh doanh nhằm tối đa hóa lợi nhuận. Hơn nữa, nghiên cứu là nguồn tài liệu bổ ung cho các lĩnh vực nghiên cứu còn hạn chế về phân tích thị trường trong ngành thủy sản Việt Nam và là cơ sở để mở rộng nghiên cứu cho các đối tượng thủy sản khác.

\section{Cơ sở lý thuyết và tổng quan tài liệu}

\subsection{Co sở lý thuyết}

Mối quan hệ giữa giá thế giới và giá trong nước được bàn đến đầu tiên bởi Mundlak và Larson (1992). Tiếp theo đó, phân tích mối quan hệ giữa giá qua các khâu trung gian trong chuỗi cung ứng và chuỗi giá trị. Các nghiên cứu này tập trung vào phân tích sự chênh lệch giá giữa các giai đoạn khác nhau trong thị trường do ảnh hưởng bởi sức mạnh thị trường, chi phí vận chuyển và chi phí giao dịch, lợi nhuận tăng thêm theo quy mô sản xuất, sự đồng nhất và tính khác biệt của sản phẩm, tỷ giá hối đoái và các chính sách.

\subsubsection{Sụ truyền dẫn giá thế giới và giá nộ địa}

Mundlak và Larson (1992) xem xét mối quan hệ giữa giá nông sản trong nước và giá nông sản thế giới. Các tác giả tập trung vào khai thác sự biến động của giá thế giới đến giá trong nước và đo lường ảnh hưởng giá do tỷ giá hối đoái và lạm phát gây ra theo quy luật một giá (Law of One Price -LOP). Theo Parsley và Wei (1996), quy luật một giá được hiểu trong điều kiện thương mại tự do không có các rào cản thương mại, chi phí vận chuyển, thuế, ... thì các hàng hoá giống hệt nhau trên các thị trường khác nhau sẽ có giá như nhau khi quy về cùng một đồng tiền. Tuy nhiên, tác động của các chiến lược phân biệt giá của các doanh nghiệp và cấu 
trúc thị trường có liên quan và các chính sách hạn chế xuất nhập khẩu (thuế, hàng rào kỹ thuật, ...) gây ra khác biệt giữa giá trong và ngoài nước (Froot \& Klemperer, 1988).

Các doanh nghiệp xuất khẩu có vị thế trên thị trường thế giới xây dựng nhiều mức giá khác nhau cho nhiều dòng sản phẩm phục vụ cho các thị trường khác biệt về nhu cầu. Cụ thể như thị trường khó tính với rào cản về tiêu chuẩn chất kháng sinh (Nhật Bản, EU), sản phẩm nhập khẩu bị thắt chặt về chất lượng và tiêu chuẩn kỹ thuật rất khắt khe nên sản phẩm của các doanh nghiệp xuất khẩu được định giá xuất cao hoặc cao hơn rất nhiều so với giá của sản phẩm phổ thông xuất qua thị trường dễ tính (Trung Quốc) (VASEP, 2017).

Để tạo được vị thế trên thị trường các doanh nghiệp chế biến-xuất khẩu thực hiện đa dạng hóa sản phẩm, không ngừng cải tiến chất lượng sản phẩm. Đồng thời, các doanh nghiệp xuất khẩu chú trọng hơn về hình thức sản phẩm như bao bì và logo riêng của doanh nghiệp nhằm nâng cao giá trị thương hiệu và đáp ứng khác biệt sở thích giữa các thị trường quốc tế (Bộ Công Thương, 2017; VASEP, 2015).

Doanh nghiệp xuất khẩu tại mỗi quốc gia khi gia nhập vào thị trường thương mại quốc tế phải chịu thuế và kiểm định xuất khẩu khác nhau. Đây là phần chi phí trực tiếp thêm gánh nặng về chi phí của các doanh nghiệp xuất khẩu. Ảnh hưởng đến sức cạnh tranh giữa các doanh nghiệp xuất khẩu trên thị trường thương mại quốc tế (VASEP, 2017).

\subsubsection{Sụ truyền dẫn giá giũa các thị truờng riêng biệt trong chuỗi giá trị}

Mỗi giai đoạn khác nhau trong chuỗi giá trị nông sản hình thành những thị trường riêng biệt (Norwood \& Lusk, 2008). Theo Fackler và Goodwin (2001), giá của một hàng hóa ở hai thị trường tách biệt ngoài việc phụ thuộc chi phí giao dịch, chi phí vận chuyển còn phụ thuộc vào thuế, chi phí chế biến và sức mạnh thị trường của người mua hay người bán. Một khi các tác nhân trong chuỗi cung ứng thực hiện được chức năng tạo ra sản phẩm giá trị gia tăng, sản phẩm đạt chuẩn chất lượng thì khoảng chênh lệch giá giữa các thị trường là rất lớn. Phân tích việc truyền dẫn giá trong chuỗi giá trị được thực hiện bằng cách xem xét mối quan hệ giữa giá của sản phẩm qua mỗi khâu khác nhau trong chuỗi. Giá của sản phẩm giữa các thị trường có mối quan hệ với nhau khi đó sự truyền dẫn giá giữa các thị trường xuất hiện. Điều đó có nghĩa là giá giữa các thị trường có sự liên kết.

Theo Fackler và Goodwin (2001), giá sản phẩm i của thị trường 1 khác với giá sản phẩm i ở thị trường 2 là do chi phí phát sinh trong quá trình phân phối. Nếu chi phí vận chuyển và chi phí giao dịch của một hàng hóa ở hai thị trường tách biệt là $c$, mối quan hệ giữa giá hàng hóa $\mathrm{i}$ giữa 2 thị trường là $P_{1 \mathrm{i}}=P_{2 \mathrm{i}}+c($ Enke, 1951).

Người có sức mạnh thị trường chính là người định giá sản phẩm. Vì vậy, sức mạnh thị trường thuộc vào người mua hay người bán thật sự tác động đến khoản chênh lệch giá giữa hai thị trường (McCorriston, Morgan, \& Rayner, 2000). Hơn nữa, những chính sách (thuế, lệ phí, vấn đề an toàn thực phẩm, liên kết, ...) làm phát sinh thêm chi phí liên quan đến việc định giá cũng ảnh hưởng đến giá giữa các khâu trong chuỗi giá trị (Thompson, Sul, \& Bohl, 2002). Tất cả những yếu tố này góp phần làm tăng thêm chi phí phát sinh trong chuỗi cung ứng của sản phẩm. 
Các chuỗi số liệu giá được cho là truyền dẫn khi những thay đổi về giá trong một thị trường được chuyển sang thị trường kia tại mọi thời điểm. Tuy nhiên trong thực tế, truyền dẫn giá không phải lúc nào cũng có tác động tức thời hoặc sau khoảng thời gian mà chỉ xảy ra trong dài hạn (Balcombe và Morisson, 2002). Thông thường, tồn tại mối quan hệ của các chuỗi số liệu giá với độ trễ của chuỗi số liệu trong quá khứ và giá sản phẩm tại các thị trường. Do các chuỗi số liệu kinh tế theo thời gian, như số liệu về giá trong nghiên cứu này, thường không đảm bảo thuộc tính dì̀ng, nên phương pháp OLS thường dùng trong hồi quy tuyến tính thường không cho kết quả đáng tin cậy do hiện tượng hồi quy giả (Granger và Newbold, 1974). Lý thuyết đồng liên kết được phát triển bởi Granger (1981) và hoàn thiện bởi Engle và Granger (1987) được áp dụng cho trường hợp chuỗi không dừng. Đến năm 1996, Barrett tiến hành phân tích giá động dựa vào sự hình thành giá trên thị trường và những cú sốc giá tác động đến thị trường khác của sản phẩm nông nghiệp. Từ đó, ý thuyết này được áp dụng phổ biến trong phân tích quan hệ giữa các biến số kinh tế sử dụng dữ liệu theo dãy số thời gian đặc biệt đối với nông sản. Vì vậy, tiếp cận theo hướng đồng tích hợp và ước ượng VECM, ECM là phương pháp phù hợp.

\subsection{Tổng quan tài liệu}

Sự truyền dẫn giá giữa những thị trường riêng biệt trong một kênh phân phối nông sản được nghiên cứu rất phổ biến trên thế giới (Norwood \& Lusk, 2008). Trong nghiên cứu về thị trường cá tuyết ở Na-uy, Asche và cộng sự (2002) cho thấy mối quan hệ đồng liên kết giữa giá ở các giai đoạn (thị trường) khác nhau trong chuỗi giá trị như giá cá được bán ngay tại tàu và giá tại thị trường nội địa và xuất khẩu và các mức giá này có khuynh hướng thay đổi cùng với nhau theo một tỷ lệ nào đó. Bên cạnh đó, G. V. Nguyen (2010) đã khẳng định có sự truyền dẫn về giá cá nheo bán sỉ và giá cá đã chế biến ở Hoa Kỳ đến giá cổng trại. D. M. Nguyen (2012) cũng chỉ ra rằng khi giá bán sỉ tăng thì giá tôm sú bán tại cổng trại được dự báo tăng cả trong ngắn hạn và dài hạn. Giá xuất khẩu được dự báo, trong ngắn hạn, không đủ ý nghĩa thống kê để tạo ra một ảnh hưởng đáng kể đến giá tôm sú bán tại cổng trại. Tuy nhiên, trong dài hạn, giá tôm sú bán tại cổng trại được dự báo sẽ tăng, giá xuất khẩu tăng nhưng không bị ảnh hưởng bởi giá tôm bán lẻ và yếu tố mùa vụ.

Ngoài ra, việc truyền giá bị ảnh hưởng bởi hiệu quả và mức độ các tác nhân tham gia trong chuỗi (Aramyan \& Kuiper, 2009; Bunte, 2006; Swinnen \& Vandeplas, 2014). Trong đó, mối quan hệ giá giữa các tác nhân trong chuỗi giá trị của sản phẩm liên quan đến chi phí phát sinh (vận chuyển, đóng gói, phân loại, ...), cấu trúc thị trường và tổ chức phân phối (dự trữ, thu gom, chế biến), sức mạnh thị trường thuộc về người mua hay người bán (G. V. Nguyen, 2010; Bakucs, Fałkowski, \& Ferto, 2014).

Mundlak và Larson (1992), sử dụng số liệu chuỗi thời gian với kiểm định đồng liên kết và mô hình $\mathrm{ECM}$ về các mặt hàng nông nghiệp tại hai thị trường nội địa và xuất khẩu nhằm xem xét mối quan hệ giữa giá trong nước và giá thế giới, cho thấy sự biến động của giá thế giới là một yếu tố quan trọng tác động đến giá trong nước. Trong khi đó, các yếu tố lãi suất và lạm phát là những nhân tố góp phần ảnh hưởng biên độ dao động giá nông sản trong nước $\mathrm{P}$. $\mathrm{V}$. Nguyen và To (2014). Phân tích truyền dẫn giá sản phẩm nông nghiệp trong nước và giá quốc tế nhằm đánh giá khả năng hội nhập thị trường, khả năng cạnh tranh và sức mạnh thị trường 
của nước xuất khẩu trên thị trường thế giới. Phần lớn nghiên cứu là cơ sở cho các nhà hoạch định, dự báo giá cả thị trường, chính sách kinh tế đưa ra các iện pháp can thiệp nhằm tăng thu nhập ở nông thôn (Conforti, Hallam, \& Rapsomanikis, 2003).

Trong nghiên cứu này, kiểm định Dickey-Fuller và mô hình OLS và hiệu chỉnh sai số (ECM - Error Correction Model) được sử dụng để kiểm định tính dừng của các chuỗi giá và ước lượng các tác động dài hạn và ngắn hạn của giá tôm sú xuất khẩu và giá tại thị trường nội địa (bán lẻ) đối với giá cổng trại.

\section{Phương pháp phân tích và số liệu nghiên cứu}

\subsection{Mô hình nghiên cúu}

Chuỗi số liệu thời gian thường không đảm bảo thuộc tính dừng. Do vậy, von CramonTaubadel và Loy (1999) đã phát triển những phương pháp khắc phục sai sót trên dựa trên khái niệm đồng liên kết được phát triển bởi Engle và Granger (1987) và Johansen (1988). Theo lý thuyết về đồng liên kết, tác động của giá tôm sú xuất khẩu và giá bán lẻ tại thị trường nội địa đối với giá tôm sú bán tại cổng trại được dự báo thông qua mô hình hiệu chỉnh sai số. Mô hình thực nghiệm trong nghiên cứu này có dạng:

$$
\Delta \mathrm{Pta}_{\mathrm{it}}=\alpha_{0}+\alpha_{1} \Delta \mathrm{Pxk}_{\mathrm{it}}+\alpha_{2} \Delta \mathrm{Pbl}_{\mathrm{it}}+\beta u_{\mathrm{t}-1}+\varepsilon_{t}
$$

Trong đó:

$\Delta$ là sai phân về giá giữa hai giai đoạn (tháng) thứ t và t-1;

$i$ đại diện cho thị trường bán lẻ nội địa và thị trường xuất khẩu;

$\alpha_{\mathrm{i}}$ là hệ số thể hiện mối liên kết giữa giá xuất khẩu, giá bán lẻ tại thị trường nội địa đối với giá tôm sú bán tại cổng trại;

$\beta$ là hệ số thể hiện tốc độ điều chỉnh giá trong ngắn hạn để đạt trạng thái cân bằng.

\section{Các kiểm định cần thực hiện:}

Với số liệu chuỗi thời gian, nghiên cứu sử dụng phương pháp kiểm định $\mathrm{ADF}$ (Augmented Dickey - Fuller test) và Phillips - Perrron để xác định tính dừng. Nếu các chuỗi cùng dừng sau khi lấy sai phân bậc 1 ; tiếp theo cần xác định trật tự tích hợp của các biến (integration order) bằng kiểm định đồng liên kết của Johansen để đo lường mối quan hệ trong dài hạn giữa các biến.

Chuỗi số liệu sau khi được kiểm định tính dừng ở chuỗi gốc sẽ tiến hành ước ượng mô hình hiệu chỉnh sai số (Error Correction Model - $\mathrm{ECM}$ ) và mô hình OLS để đo lường mối quan hệ trong ngắn hạn và dài hạn giữa các biến. Trước khi diễn giải kết quả từ mô hình cần tiến hành các kiểm định tính dừng phần dư và tự tương quan.

\subsection{Số liệu nghiên cúu}

Nghiên cứu này sử dụng chuỗi số liệu thời gian giá tôm theo tháng từ tháng 9 năm 2011 đến tháng 4 năm 2017 với tổng cộng 68 quan sát được thu thập tại các thị trường tỉnh Cà Mau. Cà Mau là tỉnh đi đầu trong lĩnh vực nuôi trồng, chế biến, xuất khẩu tôm trong cả nước. Tỉnh có diện tích nuôi tôm Sú lớn nhất vùng với $47,2 \%$ tổng diện tích nuôi tôm Sú và sản lượng 
chiếm 37,9\% tổng sản lượng vùng (Bộ NN\&PTNT \& Viện Kinh tế và Quy hoạch thủy sản, 2015). Tính riêng năm 2007 giá trị xuất khẩu tôm Cà Mau 572 triệu USD, chiếm $44 \%$ vùng ĐBSCL. Đến năm 2014 Cà Mau giá trị kim ngạch xuất khẩu tôm đạt 1,3 tỷ USD, chiếm 50\% của vùng ĐBSCL (Bộ NN\&PTNT \& Viện Kinh tế và Quy hoạch thủy sản, 2015).

Chuỗi số liệu giá tôm trong nghiên cứu là giá tôm trung bình của cỡ tôm 30-40 con/kg tại các thị trường (bán lẻ, cổng trại và xuất khẩu) và là chuỗi số liệu dài nhất hiện các cơ quan quản lý lưu giữ. Trong đó, chuỗi số liệu giá tại cổng trại là giá xuất khẩu (FOB) của tôm sú được Cục Thống kê tỉnh Cà Mau cung cấp. Giá bán lẻ được thu thập từ chợ Nông sản Thực phẩm Cà $\mathrm{Mau}^{2}$ do Sở Tài Chính tỉnh Cà Mau thực hiện và được ngành chức năng thống nhất (Cục Thống kê tỉnh). Sở Tài Chính là cơ quan công tố, quản lý và báo cáo về Ủy ban nhân dân tỉnh và Bộ Tài Chính định kỳ hàng tháng.

\section{Kết quả - thảo luận}

\subsection{Sụ biến động của các chuỗi số liệu giá tôm sú trong thị truờng}

Trong khoảng thời gian từ tháng 9 năm 2011 đến tháng 4 năm 2017, giá tôm sú tại tỉnh Cà Mau biến động theo thời gian và tốc độ tăng giá giữa 3 thị trường (tại cổng trại, bán lẻ, xuất khẩu) khác nhau. Nhìn chung, trong khi giá tôm xuất khẩu, giá cổng trại, và giá bán lẻ giữa các thị trường có sự chênh lệch nhất định; giá xuất khẩu luôn cao hơn giá tại cổng trại và giá bán lẻ. Riêng năm 2012, giá xuất khẩu có những tháng gần bằng với giá tại cổng trại và thấp hơn giá bán lẻ nội địa. Nguyên nhân do nhu cầu tiêu thụ trên thị trường thế giới giảm mạnh và sức cạnh tranh của tôm Việt $\mathrm{Nam}_{\text {giảm }}{ }^{3}$. Xuất khẩu tôm Việt Nam vào thị trường Nhật bị ảnh hưởng nghiêm trọng. Đối với thị trường trong nước, tôm sú bị ảnh hưởng nghiêm trọng bởi dịch bệnh hội chứng tôm chết sớm (ESM) trên diện rộng ngay từ những vụ nuôi đầu tiên. Diện tích tôm sú thiệt hại do bệnh cả nước khoảng 91.174 ha. Điều đó dẫn đến nguồn tôm nguyên liệu bất ổn, đặc biệt các doanh nghiệp CBTSXK thiếu hụt nguyên liệu trầm trọng cộng với ảnh hưởng từ các chính sách bất lợi như chi phí kiểm dịch tăng, tín dụng bị thắt chặt khiến nhu cầu thu mua tôm nguyên liệu cho chế biến giảm, dẫn đến giá tôm nguyên liệu giảm mạnh tháng 12/2012 đến tháng 6/2013 (Bộ NN\&PTNT \& Viện Kinh tế và Quy hoạch thủy sản, 2015; VASEP, 2012).

Những tháng đầu năm 2014, Việt Nam vẫn duy trì được vị trí dẫn đầu về cung cấp tôm cho thị trường Mỹ với sản ượng xuất khẩu 206 nghìn tấn tôm trong 5 tháng đầu năm, tăng 9\% so với cùng kỳ năm 2013. Giá xuất khẩu trung bình đạt $12,5 \mathrm{USD} / \mathrm{kg}$, tăng $40 \%$. Tuy nhiên trên thực tế, tình hình tiêu thụ tôm trên thế giới trong giai đoạn này lại chưa ổn định nên đã làm cho sự thay đổi giá tôm xuất khẩu của Việt Nam qua từng tháng có nhiều biến động. Những tháng đầu năm 2015, giá tôm xuất khẩu chủ yếu sang Trung Quốc và Hàn Quốc giảm lần ượt $28 \%$ và 17\%. Nhu cầu nhập khẩu tôm của thị trường Trung Quốc năm 2015 giảm do bất ổn kinh tế và sự sụp đổ thị trường chứng khoán đã khiến cho sức tiêu thụ của tầng lớp trung và thượng lưu nước này giảm mạnh trong thời gian tới. Tại thị trường Nhật Bản và EU, sản lượng tôm xuất khẩu giảm lần lượt $19 \%$ và $14 \%$ do đồng Yên và đồng Euro giảm giá mạnh so với đồng USD

\footnotetext{
${ }^{2}$ Là chợ cung cấp nông sản và thực phẩm lớn nhất tại thành phố Cà Mau, tỉnh Cà Mau

${ }^{3}$ Cộng thêm dịch bệnh và chi phí sản xuất tôm Việt Nam tăng và cao hơn so với Thái Lan, Ecuador và Indonesia từ 15-25\%. Đặc biệt là rào cản Ethoxyquin kiểm tra 100\% đối với tôm Việt Nam nhập vào Nhật Bản.
} 
khiến các nhà nhập khẩu hạn chế mua vào hoặc tìm cách hạ giá nhập. Tại thị trường Mỹ mặc dù nhu cầu nhập khẩu tôm của Mỹ vẫn tăng nhưng giá giảm 20\% từ 12,5 USD/kg xuống còn 10,0 USD/kg (VASEP, 2014, 2015).

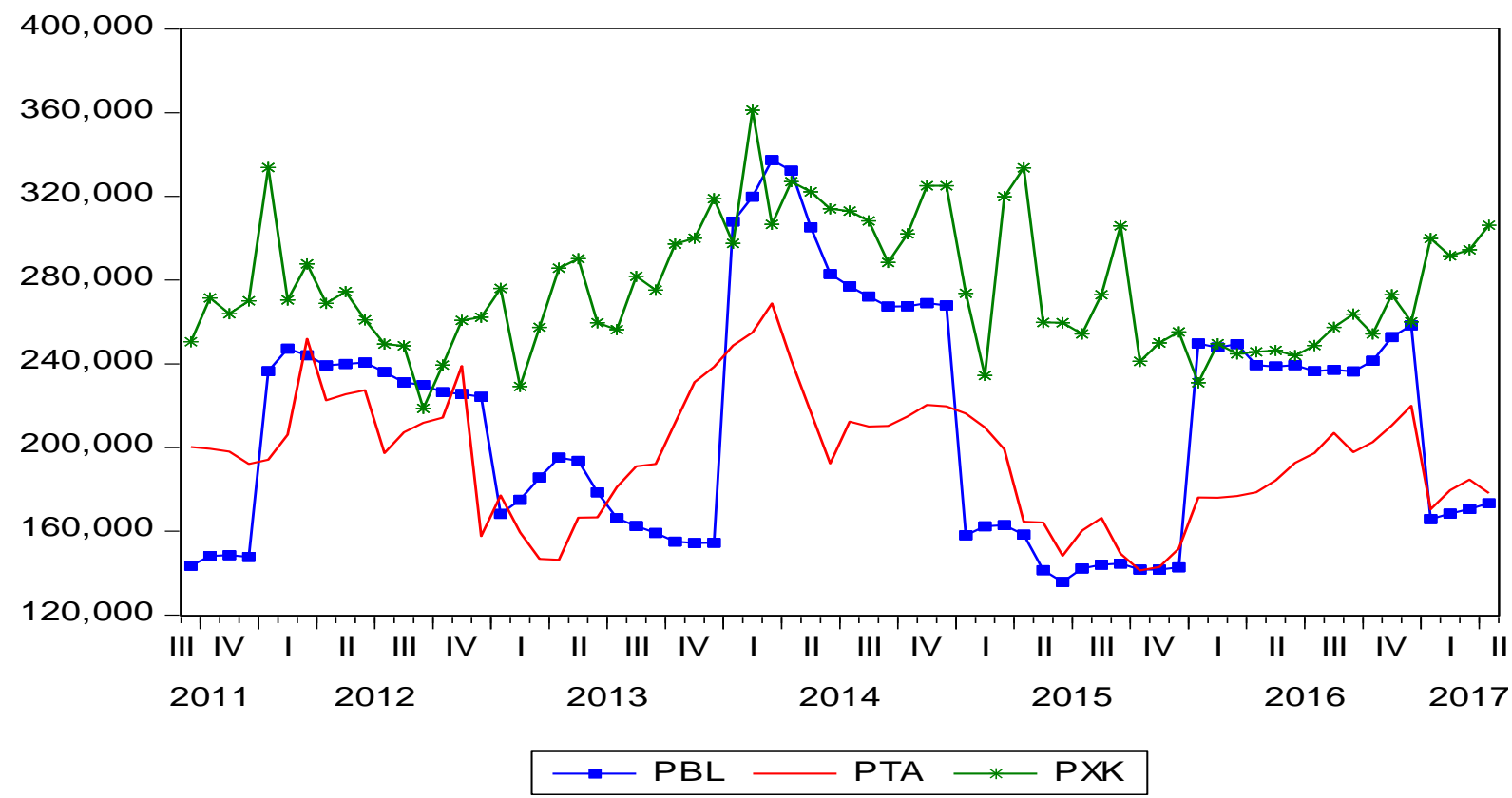

Hình 1. Các chuỗi số liệu giá tôm sú trong thị trường ( $\mathrm{VNĐ} / \mathrm{kg})$

Nguồn: Tổng hợp kết quả từ các nguồn số liệu

\subsection{Thống kê mô tả của các biến số trong mô hình}

Bảng 1 trình bày thống kê mô tả của các biến số giá. Độ lệch chuẩn của các biến số tương đối nhỏ, cho thấy sự biến động về giá giữa các kỳ không đáng kể. Tuy nhiên, chuỗi giá bán lẻ có độ lệch chuẩn xấp xỉ gấp 2 lần độ biến động của các chuỗi giá xuất khẩu và giá tại cổng trại. Điều này cho thấy chuỗi số liệu giá bán lẻ biến động theo thời gian lớn hơn so với chuỗi số liệu giá xuất khẩu và chuỗi số liệu giá tại cổng trại, nghĩa là, chuỗi số liệu giá bán lẻ gặp nhiều cú sốc hơn hai chuỗi còn lại. Bên cạnh đó, tại thị trường nội địa, giá trị nhỏ nhất của giá bán lẻ à $135.819 \mathrm{VNĐ} / \mathrm{kg}$ thấp hơn giá trị nhỏ nhất của giá tại cổng trại là $141.314 \mathrm{VNĐ} / \mathrm{kg}$. Như vậy, điều này thể hiện thị trường bán lẻ gặp rủi ro cao về giá; không phải lúc nào giá bán tại thị trường tiêu dùng cũng luôn cao hơn giá tại cổng trại.

\section{Bảng 1}

Thống kê mô tả của các biến trong mô hình

\begin{tabular}{clcccccc}
\hline $\begin{array}{c}\text { Biến } \\
\text { số }\end{array}$ & Định nghĩa biến & $\begin{array}{c}\text { Quan } \\
\text { sát }\end{array}$ & ĐVT & $\begin{array}{c}\text { Trung } \\
\text { bình }\end{array}$ & $\begin{array}{c}\text { Giá trị } \\
\text { cao nhất }\end{array}$ & $\begin{array}{c}\text { Giá trị } \\
\text { nhỏ } \\
\text { nhất }\end{array}$ & $\begin{array}{c}\text { Độn } \\
\text { lẹ̣ch } \\
\text { chuẩn }\end{array}$ \\
\hline $\mathrm{P}_{\mathrm{xk}}$ & Giá sú $\mathrm{XKBQ}$ & 68 & $\mathrm{VNĐ/kg}$ & 276.812 & 361.264 & 218.798 & 30.462 \\
$\mathrm{P}_{\mathrm{bl}}$ & Giá bán lẻ $\mathrm{BQ}$ & 68 & $\mathrm{VNĐ/} \mathrm{kg}$ & 210.968 & 337.364 & 135.819 & 54.925 \\
$\mathrm{P}_{\mathrm{ta}}$ & Giá cổng trại $\mathrm{BQ}$ & 68 & $\mathrm{VNĐ} / \mathrm{kg}$ & 195.777 & 268.872 & 141.314 & 29.657 \\
\hline
\end{tabular}

Nguồn: Tổng hợp kết quả từ các nguồn số liệu 


\subsection{Kiểm định tính dùng các chuỗi số liệu}

Bảng 2 trình bày các kết quả kiểm định tính dừng của các chuỗi giá trong giai đoạn khảo sát. Các kết quả kiểm định cho thấy chuỗi số liệu giá bán lẻ $\left(\mathrm{P}_{\mathrm{bl}}\right)$, giá cổng trại $\left(\mathrm{P}_{\mathrm{ta}}\right)$ và giá xuất khẩu $\left(\mathrm{P}_{\mathrm{xk}}\right)$ của tôm đều dừng ở chuỗi gốc với mức ý nghĩa thống kê $1 \%$ và $10 \%$. Do các chuỗi đều dừng, việc hồi quy giữa các chuỗi có thể tránh được hiện tượng hồi quy giả mạo.

\section{Bảng 2}

Kiểm định nghiệm đơn vị của chuỗi số liệu giá tôm sú trong thị trường

\begin{tabular}{lcc}
\hline \multicolumn{1}{c}{ Các biến } & Kiểm định ADF & Kiểm định Phillips - Perrron \\
\cline { 2 - 3 } & Pr $>\chi^{2}$ & \multicolumn{1}{c}{$\operatorname{Pr}>\chi^{2}$} \\
\hline Giá bán lẻ tôm sú $\left(\mathrm{P}_{\mathrm{bl}}\right)$ & $0,0892^{*}$ & $0,0539^{*}$ \\
Giá cổng trại tôm sú $\left(\mathrm{P}_{\mathrm{ta}}\right)$ & $0,0965^{*}$ & $0,0787^{*}$ \\
Giá xuất khẩu tôm sú $\left(\mathrm{P}_{\mathrm{xk}}\right)$ & $0,0006^{* * *}$ & $0,0009^{* * *}$ \\
\hline
\end{tabular}

Ghi chú: *, *** lần lượt tương ứng với mức ý nghĩa thống kê $10 \%$ và $1 \%$.

Nguồn: Tổng hợp kết quả kiểm định

\subsection{Mối quan hệ giữa các giá tôm sú trên thị truò̀ng}

4.4.1. Mối quan hệ trong dài hạn giũa giá tại cổng trại với giá bán lẻ và giá xuất khẩu

Bảng 3 trình bày kết quả ước lượng mô hình hồi quy bằng OLS giữa giá tại cổng trại với giá bán lẻ nội địa và giá xuất khẩu của tôm sú. Do các chuỗi giá đều dừng, hiện tượng hồi quy giả có thể được loại bỏ. Kết quả ước lượng OLS cho thấy mô hình bị vi phạm giả định về tự tương quan nên tác giả điều chỉnh bằng mô hình với sai số chuẩn của Newey-West. Hệ số xác định $\mathrm{R}^{2}$ là 0,42 nghĩa là giá bán lẻ và giá xuất khẩu giải thích $42 \%$ sự biến động của giá cổng trại. Tất cả các hệ số ước lượng trong mô hình đều có ý nghĩa thống kê ở mức $1 \%$ hay $10 \%$, chứng tỏ, giá tại cổng trại chịu sự ảnh hưởng của giá bán lẻ và giá xuất khẩu hay tồn tại mối quan hệ dài hạn giữa giá cổng trại và các mức giá khác (D. M. Nguyen, 2012). Mức ý nghĩa thống kê của hệ số giá bán lẻ là $1 \%$ cho thấy ảnh hưởng của giá bán lẻ đến giá cổng trại tương đối mạnh hơn so với giá xuất khẩu.

Hệ số ước lượng của giá bán lẻ và giá xuất khẩu đều dương, cho thấy có sự truyền dẫn giá thuận chiều giữa các mức giá, hay sự tăng của giá bán lẻ và giá xuất khẩu sẽ dẫn đến sự gia tăng của giá cổng trại. Kết quả này tương đồng với những nghiên cứu trong và ngoài nước về mối liên kết giá ở các thị trường nông sản như Asche và cộng sự (2002) đối với cá tuyết tại Nauy, G. V. Nguyen (2010) đối với cá nheo tại thị trường Mỹ cũng như nghiên cứu của $\mathrm{D}$. M. Nguyen (2012) đối với tôm sú tại ĐBSCL và Nguyễn Hồng Phúc và cộng sự (2014) đối với cà phê tại Việt Nam. 


\section{Bảng 3}

Mối quan hệ giữa các chuỗi giá bán tôm sú trong dài hạn

\begin{tabular}{lcccc}
\hline & \multicolumn{2}{c}{ Mố hình OLS } & \multicolumn{2}{c}{ Mô hình Newey-West } \\
\cline { 2 - 5 } \multicolumn{1}{c}{ Biến số } & \multicolumn{1}{c}{ Hệ số } & Thống kê t & Hệ số & Thống kê t \\
\hline $\mathrm{P}_{\mathrm{bl}}$ & $0,300^{* * *}$ & 5,65 & $0,300^{* * *}$ & 4,54 \\
$\mathrm{P}_{\mathrm{xk}}$ & $0,204^{* *}$ & 2,12 & $0,204^{* *}$ & 1,82 \\
Hằng số & $76.078^{* * *}$ & 2,93 & $76.078^{* * *}$ & 2,71 \\
\hline $\mathrm{R}^{2}$ & & 0,42 & & 0,42 \\
Giá trị thống kê $\mathrm{F}$ & & 23,30 & & 19,49 \\
Mức ý nghĩa $\mathrm{F}$ & & 0,000 & & 0,000 \\
Thống kê Durbin-Watson & & 0,75 & & \\
\hline
\end{tabular}

Ghi chú: *,**,*** lần lượt tương ứng với mức ý nghĩa thống kê $10 \%, 5 \%, 1 \%$.

Nguồn: Tổng hợp kết quả ước lượng

Hệ số giá bán lẻ thực $\mathrm{P}_{\mathrm{bl}}$ có giá trị 0,3 , chứng tỏ trong dài hạn, khi các yếu tố khác không đổi nếu giá bán lẻ thực tăng lên 1.000 đồng thì giá tại cổng trại thực của tôm sú được dự báo tăng lên 300 đồng; trong khi đó tác động biên của giá xuất khẩu thực $\mathrm{P}_{\mathrm{xk}}$ chỉ có 0,2 với mức ý nghĩa thống kê là $10 \%$. Mức độ ảnh hưởng của giá xuất khẩu thực đến giá tại cổng trại thực nhỏ hơn so với giá bán lẻ nội địa.

Dựa vào kết quả ước lượng trong Bảng 3 , hệ số co giãn của giá cổng trại theo giá bán lẻ và giá xuất khẩu tại các mức giá hiện hành (tháng 4/2017) được ước tính lần lượt là 0,27 và 0,33 và đều có ý nghĩa thống kê ở mức $5 \%$. Kết quả này cho thấy, giá cổng trại tương đối kém co giãn đối với giá bán lẻ và giá xuất khẩu hay độ lớn của ảnh hưởng giá bán lẻ và giá xuất khẩu đến giá cổng trại tương đối nhỏ. Điều đó cho thấy việc truyền dẫn giá không hoàn hảo. Đây có thể được xem như là bằng chứng cho sự thất bại của thị trường trong việc truyền dẫn giá và do vậy đòi hỏi các can thiệp chính sách để nâng cao phúc lợi của nông dân (Conforti et al., 2003).

\subsubsection{Mối quan hệ trong ngắn hạn giũa giá tại ao với giá bán lẻ và giá xuất khẩu}

Phân tích mối quan hệ giữa giá tại cổng trại với giá bán lẻ nội địa và giá xuất khẩu trong ngắn hạn được phân tích bằng mô hình ECM. Kết quả kiểm định được trình bày tại Bảng 5 , cho thấy giá trị kiểm định tính dừng phần dư $\left(\mathrm{e}_{\mathrm{t}}\right)$ của mô hình $\mathrm{ECM}$ dựa vào kiểm định của DickeyFuller và $\mathrm{PP}$ với giá trị tới hạn $1 \%$, như vậy phần dư của mô hình có tính dừng. Đồng thời, kết quả ước lượng được trình bày tại Bảng 4 , giá trị kiểm định $d$-Durbin-Watson của mô hình xấp xỉ 2 , cho thấy mô hình không bị tự tương quan. Vì vậy, phần dư e $\mathrm{e}_{\mathrm{t}}$ của mô hình $\mathrm{ECM}$ là một nhiễu trắng, thỏa mãn các giả định của mô hình hồi quy tuyến tính cổ điển. Khi đó, kết quả ước lượng mô hình sẽ là không chệch tuyến tính tốt nhất. Ước lượng từ mô hình ECM là đáng tin cậy. 


\section{Bảng 4}

Mối quan hệ giữa các chuỗi giá bán tôm sú trong ngắn hạn

\begin{tabular}{lrr}
\hline \multicolumn{1}{c}{ Biến số } & \multicolumn{2}{c}{ Mô hình ECM } \\
\cline { 2 - 3 } & \multicolumn{1}{c}{ Hệ số } & Thống kê t \\
\hline$\Delta \mathrm{P}_{\mathrm{bl}}$ & $0,18^{* * *}$ & 3,02 \\
$\Delta \mathrm{P}_{\mathrm{xk}}$ & 0,02 & $-0,08$ \\
$\mathrm{ECM}$ & $-0,31^{* *}$ & $-2,27$ \\
$\mathrm{Hằng} \mathrm{số}$ & $-373,24$ & $-0,18$ \\
\hline $\mathrm{R}^{2}$ & & 0,20 \\
Giá trị thống kê $\mathrm{F}$ & & 5,14 \\
Mức ý nghĩa của $\mathrm{F}$ & & 0,00 \\
Thống kê Durbin-Watson & & 2,15 \\
\hline
\end{tabular}

Ghi chú: **,*** lần lượt tương ứng với mức ý nghĩa thống kê $5 \%, 1 \%$.

Nguồn: Tổng hợp kết quả ước lượng

\section{Bảng 5}

Kiểm định tính dừng của phần dư

\begin{tabular}{lcccc}
\hline \multicolumn{1}{c}{ Phương pháp } & $\begin{array}{c}\text { Chỉ tiêu kiểm } \\
\text { định }\end{array}$ & $\begin{array}{c}\text { Giá trị tới } \\
\text { hạn ở 1\% }\end{array}$ & $\begin{array}{c}\text { Giá trị tới hạn } \\
\mathbf{0} \mathbf{5 \%}\end{array}$ & $\begin{array}{c}\text { Giá trị tới } \\
\text { hạn ở 10\% }\end{array}$ \\
\hline ADF - Fisher Chi-square & $-4,665^{* * *}$ & $-3,556$ & $-2,916$ & $-2,593$ \\
PP - Fisher Chi-square & $-4.596^{* * *}$ & $-3,556$ & $-2,916$ & $-2,593$ \\
\hline
\end{tabular}

Ghi chú: *,**,*** lần lượt tương ứng với mức ý nghĩa thống kê $10 \%, 5 \%, 1 \%$.

Nguồn: Tổng hợp kết quả kiểm định

Kết quả ước lượng được trình bày tại Bảng 4, cho thấy hệ thống ước lượng của ECM có ý nghĩa thống kê ở mức $5 \%$ và âm. Như vậy, sự mất cân bằng của giá cổng trại trên thị trường trong tháng trước sẽ được điều chỉnh theo chiều ngược lại trong tháng sau, hay cụ thể hơn, khi giá cổng trại trong kỳ trước cao hơn mức cân bằng giữa các giá, các nhà thu mua sẽ có xu hướng điều chỉnh giảm giá cổng trại trong kỳ sau và ngược lại. Điều đó cho thấy việc truyền tải giá giữa các thị trường xuất khẩu và bán lẻ đến cổng trại có thể được điều chỉnh qua các kỳ. Do tôm sú từ ao nuôi đến xuất khẩu qua nhiều giai đoạn trung gian khác nhau như thương lái các cấp, nhà máy chế biến, nhà kinh doanh môi giới xuất khẩu ${ }^{4}, \ldots$ dẫn đến việc giá tôm tại cổng trại còn phụ thuộc vào nhiều chi phí khác có liên quan như chi phí cổng, chế biến, chi phí bán hàng, chi phí vận chuyển, kể cả thuế và lệ phí.

Kết quả trong Bảng 4 cũng cho thấy sự biến động của giá bán lẻ trong kỳ có ảnh hưởng lớn đến sự biến động của giá cổng trại trong kỳ, trong khi đó, sự biến động của giá xuất khẩu có ảnh hưởng không đáng kể. Kết quả này cho thấy giá bán lẻ có ảnh hưởng tức thời đến giá cổng trại trong khi đó sự truyền dẫn từ giá xuất khẩu đến giá cổng trại có thể kéo dài hàng tháng. Trong ngắn hạn, sự gia tăng của giá bán lẻ dẫn đến sự gia tăng của giá cổng trại. Tuy

\footnotetext{
${ }^{4}$ Theo WWF (2016) trong 78,62\% sản lượng tôm xuất khẩu thì có đến 72,92\% sản lượng doanh nghiệp CBTSXK mua từ thương lái/vựa
} 
nhiên, mức tăng của giá cổng trại thấp hơn nhiều so với giá bán lẻ $(0,18$ và 1$)$. Sự chênh lệch này có thể do sức mạnh thị trường của các nhà thu mua cao hơn so với người nuôi hay do các chi phí liên quan trong lưu thông hàng hóa (N. V. G. Le et al., 2012).

\section{Kết luận}

Nghiên cứu này sử dụng kiểm định nghiệm đơn vị và ước lượng mô hình hiệu chỉnh sai số ECM và mô hình OLS nhằm làm rõ mối quan hệ giữa giá tại cổng trại với giá xuất khẩu và giá bán lẻ nội địa trong ngắn hạn và dài hạn. Kết quả phân tích đã khẳng định chuỗi số liệu giá bán lẻ gặp nhiều cú sốc và rủi ro cao hơn chuỗi số liệu giá xuất khẩu và chuỗi số liệu giá cổng trại. Nghiên cứu chỉ ra rằng, tác động của giá xuất khẩu đối với giá bán tại cổng trại có ý nghĩa trong dài hạn nhưng lại không có ý nghĩa trong ngắn hạn; kết quả này tương đồng với nghiên cứu của D. M. Nguyen (2012). Trong khi đó, giá cổng trại bị tác động bởi giá bán lẻ nội địa. Đây là kết quả khác biệt so với nghiên cứu của D. M. Nguyen (2012).

Trong ngắn hạn, chuỗi số liệu giá bán lẻ nội địa có tác động tức thời và quan hệ thuận chiều đến giá tôm sú cổng trại; trong khi giá xuất khẩu thì không ảnh hưởng. Mặt khác, tốc độ hiệu chỉnh sai số trong mô hình là âm và tương đối nhỏ.

Trong dài hạn, các chuỗi số liệu giá xuất khẩu và giá bán lẻ nội địa trong thị trường có mối quan hệ thuận chiều với giá tại cổng trại. Giá bán lẻ là yếu tố ảnh hưởng mạnh và có vai trò quan trọng đối với giá tại cổng trại hơn so với giá xuất khẩu. Sự truyền tải giá từ thị trường bán lẻ và xuất khẩu đến giá cổng trại không được hoàn hảo do sức mạnh thị trường của các nhà thu mua và các chi phí lưu thông khác.

\section{Tài liệu tham khảo}

Aramyan, L. H., \& Kuiper, M. (2009). Analyzing price transmission in agri-food supply chains: An overview. Measuring Business Excellence, 13(3), 3-12.

Asche, F., Hartmann, J., Fofana, A., Jaffry, S., \& Menezes, R. (2002). Vertical relationships in the Value Chain: An Analysis Based on Price Information for cod and salmon in Europe. Retrieved October 11, 2017, from https://openaccess.nhh.no/nhhxmlui/handle/11250/164629

Balcombe, K.G., \& Morrison, J. (2002). Commodity price transmission: A critical review of techniques and an application to selected export commodities. Report to the Food and Agriculture Organization of the United Nations, Rome, Italy.

Bakucs, Z., Fałkowski, J., \& Ferto, I. (2014). Does market structure influence price transmission in the agro-food sector? A meta-analysis perspective. Journal of Agricultural Economics, 65(1), 1-25.

Bộ Công Thương. (2017). Tình hình thị truờng xuất khẩu tôm Việt Nam. Hội nghị tôm năm 2017 [The situation of Vietnam's shrimp export market. Shrimp Conference 2017]. Retrieved October 11, 2017, from https:/www.moit.gov.vn/CmsView-EcoITportlet/html/print_cms.jsp?articleId=11207 
Bộ NN\&PTNT, \& Viện Kinh tế và Quy hoạch thủy sản. (2015). Quy hoạch phát triển nuôi trồng thủy sản vùng Đồng bằng Sông Cửu Long đến năm 2020, định hướng đến năm 2030 [Aquaculture development planning for the Mekong Delta region to 2020, with an orientation to 2030]. Retrieved October 11, 2017, from https://tongcucthuysan.gov.vn/Portals/0/BAO\%20CAO\%20TOM\%20NUOC\%20LO_1. pdf

Bunte, F. (2006). Pricing and performance in agri-food supply chains. Retrieved October 12, 2017, from https://edepot.wur.nl/21090

Conforti, P., Hallam, D., \& Rapsomanikis, G. (2003). Market integration and price transmission in selected food and cash crop markets of developing countries: Review and applications. Retrieved October 13, 2017, from https://www.researchgate.net/publication/288891135_Market_Integration_and_Price_T ransmission_in_Selected_Food_and_Cash_Crop_Markets_of_Developing_Countries_R eview_and_Applications

Dickey, D. A., \& Fuller, W. A. (1979). Distribution of the estimators for autoregressive time series with a unit root. Journal of the American Statistical Association, 74(366a), 427431.

Engle, R., \& Granger, C. W. J. (1987). Co-integration and error correction: Representation, estimation, and testing. Econometrica, 55(2), 251-276.

Enke, S. (1951). Equilibrium among spatially separated markets: Solution by electric analogue. Econometrica: Journal of the Econometric Society, 19(1), 40-47.

Fackler, P., \& Goodwin, B. (2001). Spatial price analysis. In B. L. Gardner \& G. C. Rausser (Eds.), Handbook of Agricultural Economics (pp. 971-1024). Amsterdam, Netherlands: Elsevier (North Holland Publishing Co.).

Froot, K. A., \& Klemperer, P. D. (1988). Exchange rate pass-through when market share matters. The American Economic Review, 79(4), 637-654.

Granger, C. W. J. (1981). Some properties of time series data and their use in econometric model specification. Journal of Econometrics, 16(1), 121-130.

Granger, C. W. J., \& Newbold, P. (1974). Spurious regressions in econometrics. Journal of Econometrics, 2(2), 111-120.

Hendry, D. F., \& Juselius, K. (2001). Explaining cointegration analysis: Part II. The Energy Journal, 22(1), 75-120.

Hiệp hội Chế biến và Xuất khẩu Thủy sản Việt Nam (VASEP). (2012). Báo cáo ngành tôm Việt Nam năm 2012 và xu hướng năm 2013 [Report on Vietnam shrimp industry in 2012 and trends in 2013]. Retrieved October 14, 2017, from https://tepbac.com/document/full/1097/bao-cao-nganh-tom-viet-nam-nam-2012-va-xuhuong-nam-2013.htm 
Hiệp hội Chế biến và Xuất khẩu Thủy sản Việt Nam (VASEP). (2014). Báo cáo xuất khẩu thủy sản thủy sản Việt Nam quí I/2014, quí II/2014, quí III/2014 [Report on seafood export of Vietnam quarter I / 2014, quarter II / 2014, quarter III / 2014]. Retrieved October 15, 2017, from http://www.vasep.com.vn/Bao-cao-xuat-khau-thuy-san/

Hiệp hội Chế biến và Xuất khẩu Thủy sản Việt Nam (VASEP). (2015). Báo cáo xuất khẩu thủy sản thủy sản Việt Nam quí II/2015, quí III/2015 [Report on seafood export of Vietnam quarter II / 2015, quarter III / 2015]. Retrieved October 16, 2017, from http://vasep.com.vn/Bao-cao-xuat-khau-thuy-san/777_41019/BAO-CAO-XUATKHAU-THUY-SAN-VIET-NAM-QUY-II2015.htm

Hiệp hội Chế biến và Xuất khẩu Thủy sản Việt Nam (VASEP). (2017). Sản xuất và xuất khẩu tôm 2016-Dư báo năm 2017 [Shrimp production and export 2016 - Forecast for 2017]. Retrieved October 17, 2017, from http://vasep.com.vn/

Johansen, S. (1988). Statistical analysis of cointegrating vectors. Journal of Economic Dynamics and Control, 12(2/3), 231-254.

Le, N. V. G., Le, N. N. B., \& Nguyen, A. V. (2012). Thực trạng chuỗi giá trị ngành hàng tôm sú ở ĐBSCL [The current status of the value chain of black tiger shrimp in the Mekong Delta]. Tạp chí Nông nghiệp \& PTNT, 20, 71-77.

Le, S. X., Do, C. M., Nguyen, T. T., \& Nguyen, Q. T. K. (2011). Phân tích chuỗi giá trị tôm sú (penaneus monodon) ở Đồng Bằng Sông Cửu Long [Analysis of the value chain of black tiger shrimp (penaneus monodon) in the Mekong Delta]. Proceedings of Kỷ yếu Hội nghị khoa học thủy sản lần 4, 524-536.

McCorriston, S., Morgan, C. W., \& Rayner, A. J. (2000). Price transmission: The interaction between firm behaviour and returns to scale. Paper presented at University of Nottingham, Nottingham, UK.

Minot, N. (2010). Transmission of world food price changes to markets in Sub-Saharan Africa. Washington, DC: International Food Policy Research Institute.

Morales, L. E., Hoang, N., Griffith, G., \& Salcedo, S. (2015). Vertical price transmission and spillovers between agri-food chains. Academy of Taiwan Business Management Review, $11(3), 81-91$.

Mundlak, Y., \& Larson, D. F. (1992). On the transmission of world agricultural prices. The World Bank Economic Review, 6(3), 399-422.

Nguyen, D. M. (2012). Tác động của giá xuất khẩu và giá bán nội địa đến giá ao nuôi tôm Một phân tích kinh tế lượng cho tôm sú [The impact of export and domestic prices on shrimp pond prices - An econometric analysis of black tiger shrimp]. Tap chí Khoa hoc Truờng Đại học Mở Thành phố Hồ Chí Minh, 5(28), 28-38.

Nguyen, G. V. (2010). Supply response, price transmission, and risk in the U.S. catfish industry (Doctor dissertation). Auburn University, Auburn, AL. 
Nguyen, P. V., \& To, H. T. K. (2014). Kiểm định đồng liên kết giữa giá cà phê Việt Nam xuất khẩu và giá cà phê Thế giới giai đoạn 2008-2014 [Co-link test between export coffee prices of Vietnam and world coffee prices in the period 2008-2014]. Tap chí khoa hoc truòng Đại hoc Mở TP.HCM, 4(37), 30-36.

Norwood, F. B., \& Lusk, J. (2008). Agricultural marketing and price analysis. Upper Saddle River, NJ: Prentice Hall.

Parsley, D. C., \& Wei, S. J. (1996). Convergence to the law of one price without trade barriers or currency fluctuations. The Quarterly Journal of Economics, 111(4), 1211-1236.

Rapsomanikis, G., Hallam, D., \& Conforti, P. (2006). Market integration and price transmission in selected food and cash crop markets of developing countries: Review and applications. In A. Sarris \& D. Hallam (Eds.), Agricultural commodity markets and trade (pp. 187-217). Cheltenham, UK: Edward Elgar.

Swinnen, J. F., \& Vandeplas, A. (2014). Price transmission and market power in modern agricultural value chains. Retrieved October 13, 2017, from https://papers.ssrn.com/sol3/papers.cfm?abstract_id=2400431

Thompson, S. R., Sul, D., \& Bohl, M. T. (2002). Spatial market efficiency and policy regime change: seemingly unrelated error correction model estimation. American Journal of Agricultural Economics, 84(4), 1042-1053.

Tổ chức Bảo tồn Thiên nhiên Thế giới (WWF). (2016). Đánh giá dụ án chuỗi giá trị cá tra và tôm ơ ĐBSCL [Project evaluation of pangasius and shrimp value chain project in the Mekong Delta]. Retrieved October 13, 2017, from https://vietnam.panda.org/

Trung tâm Bảo tồn sinh vật Biển và phát triển cộng đồng (MCD). (2015). Chuối giá trị tôm và lồng ghép giới tại Cà Mau. Retrieved October 20, 2017, from http://mcdvietnam.org/

von Cramon-Taubadel, S., \& Loy, J. P. (1999). The identification of asymmetric price transmission processes with integrated time series. Jahrbücher für Nationalökonomie und Statistik, 218(1/2), 85-106. 